\section{Genome scientists' paths diverge}

Sequencing the human genome is a hard act to follow, and the two men who spearheaded the sequencing effort have taken different paths in the aftermath of that revolutionary biological project, just as they did to achieve the first draft of the genome in 2001. Britain's John Sulston, one of the leaders of the public sequencing consortium, has returned to basic research, and last month shared the Nobel Prize in Physiology \& Medicine for his early developmental biology work on the roundworm Caenorhabditis elegans. Craig Venter, the American who used his own DNA in the privately funded arm of the sequencing effort, plans to burn individ-

ual human genomes onto compact discs at a price tag of $\$ 500,000$ each.

Venter eventually hopes that CD genomes will be mass produced, and predicts that they will ultimately be stored in physicians' offices along with individual medical data, much as paper or computer records are catalogued today. Such CDs could be handed down from one genera-

awareness about rare diseases in the medical community." Although individual rare diseases each affect fewer than 200,000 people in the United States, taken together the 6,000 recognized rare diseases afflict around 25 million Americans.

The companion "Rare Diseases Orphan Product Development Act of 2002" would authorize a separate sum of $\$ 25$ million annually for an existing program at the Food and Drug Administration (FDA) that provides grants for small clinical trials and other research involved in developing drugs and treatments for rare diseases. This would double the current funding for the program.

This is not the first time that US Congress has shown an interest in rare diseases. The Orphan Drug Act of 1983 created financial incentives for research and production of orphan drugs. Before 1983, 38 orphan drugs had been developed; since the Orphan Drug Act, more than 220 new orphan drugs have been marketed in the United States and more than 800 additional drugs are in the pipeline.

Laura Bonetta, Bethesda tion to another within families, making genetic information valuable in future years for predicting and recognizing familial disease trends.

Aside from its cost, Venter's latest commercial venture faces practical challenges. The three gigabytes of computer space required to store a genome fits onto a small hard drive, and the three billion DNA base pairs must somehow be squeezed onto a CD. And as bioethicist Arthur Caplan articulates, "I don't think it makes any sense at

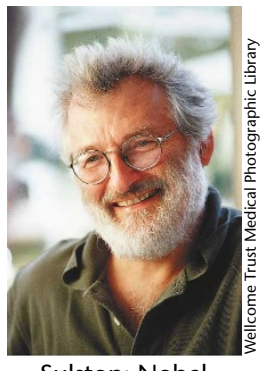

Sulston: Nobel reward for humble worm are not commercial. Venter was chairman of the Maryland-based company, Celera, that carried out the private effort to decode the human genome. He was ousted from the company in January 2002 when it switched business directions from bioinformatics to drug discovery and development. He now runs several nonprofit ventures focusing on genetic bioethical concerns and on finding energy alternatives that produce lower gas emissions. He says that profit from the CD genomes will fund these projects.

Meanwhile, Sulston shares the all to have one's genome mapped right now. There's not enough practical utility in having a map-not much can be done diagnostically, and even less therapeutically. Paying $\$ 500,000$ now is like being first on your block to own a $\$ 25,000$ high-definition TV when there are almost no transmitters broadcasting high-definition TV [signals] yet."

But Venter is not alone in trying to produce genomes on $\mathrm{CD}$. At least three other companies, including the United Kingdom's Solexa, are working on similar projects. However, he claims his motives
2002 Nobel Prize with Sydney Brenner, president of the Molecular Sciences Institute in Berkeley, California, and Robert Hovitz of the Massachusetts Institute of Technology. Brenner established C. elegans as an experimental model for the genetic analysis of organ development; Sulston described the phenomena of cell lineage and apoptosis and their importance in wholebody development; and Horvitz identified the first cell death genes, ced-3, ced-4 and ced-9, and their human homologues.

Karen Birmingham, London \&

Marlene Cimons, Washington, DC

\title{
MIM HQ moves continent
}

After three years in Bethesda, Maryland, management of the Multilateral Initiative on Malaria (MIM) moves to Sweden this month where it will be based at three Stockholm institutions: Stockholm University, the Karolinska Institute and the Swedish Institute for Infectious Disease Control. The transfer becomes official at the Third MIM PanAfrican Malaria Conference in Arusha, Tanzania.

In 1997, Harold Varmus, then director of the National Institutes of Health, argued for stepping up worldwide research on malaria, given the disease's enormous impact on global public health. The MIM was established to respond to this challenge, and was first based at the Wellcome Trust in London, with a charter that called for the Secretariat to move to a new institution every three years.

Since 1999, the Secretariat has resided at the NIH's Fogarty International Center (FIC). "The goal ultimately is to have the MIM Secretariat situated in Africa," says FIC director, Gerald Keusch. Representatives of African research institutions already make up half of the voting members, but concerns about funding shortages and a lack of infrastructure have so far kept the Secretariat in industrialized countries.

Initially, the MIM struggled to distinguish itself from other malaria research and control efforts but appears to have carved out a niche in the politically charged world of international public health. "[MIM] has been driven by scientists and science, and the orientation has been to help ensure ... the science is not co-opted or controlled by the malaria control agenda," says Keusch. While stressing that he is not criticizing efforts like the World Health Organization's (WHO) Roll Back Malaria campaign, Keusch says the MIM fought to avoid the internal and international political pressures that often accompany WHO programs.

A MIM reassessment of the worldwide burden of malaria provides sobering statistics: over 1.5 billion new infections occur annually, with 2.7 million deaths. Over $75 \%$ of the victims are African children under the age of 5 .

Alan Dove, Philadelphia 